\title{
Rouleaux formation by spermatozoa in the naked-tail armadillo, Cabassous unicinctus
}

\author{
E. Heath, N. Schaeffer*, D. A. Meritt, Jr* and R. S. Jeyendran $\dagger$ \\ Department of Veterinary Biosciences, University of Illinois, $2001 \mathrm{~S}$. Lincoln Ave., Urbana, \\ IL 61801; *Lincoln Park Zoo, 2200 N. Cannon Drive, Chicago, IL 60614; and †Institute of \\ Reproductive Medicine, 111 N. Wabash Avenue, Chicago, IL 60602, U.S.A.
}

\begin{abstract}
Summary. Spermatozoa from the ductus deferens of a naked-tail armadillo, Cabassous unicinctus, were arranged in rouleaux. The sperm heads were wafer-thin, with the acrosome and nucleus flattened together. Dense subacrosomal material in the equatorial segment of the acrosomal region was present on one surface but not on the other.
\end{abstract}

\section{Introduction}

The naked-tail or eleven-banded armadillo, Cabassous unicinctus, is an edentate in the family Dasypodidae. There are 21 species of armadillo in this family. All are found in the Americas, and almost all are both testicondid and polyembryonic (Grassé, 1955; Rowlands \& Weir, 1984). Members of the genus Cabassous may be the only exceptions in producing single offspring (Meritt, 1985). The best known dasypodid is the nine-banded armadillo (Dasypus novemcinctus) which ranges from Argentina to the southeastern United States. The ultrastructure of the spermatozoon of the nine-banded armadillo has been described (Nagy \& Edmonds, 1973). Nine-banded armadillos and several other armadillo species have been successfully bred in captivity (Miles et al., 1982), but Cabassous is not mentioned among them. Members of the genus Cabassous have a wide geographical range in South America (Peru, Brazil, Paraguay and north-eastern Argentina) and living examples have also been reported from Honduras, Costa Rica and Panama (Meritt, 1985). The spermatozoon of the naked-tail armadillo is described here for the first time.

\section{Materials and Methods}

\footnotetext{
The spermatozoa used in this study were obtained from a 3-5-year-old sexually mature naked-tail armadillo, originally caught wild in Guyana. This animal was presented to the Lincoln Park Zoo's veterinary clinic in acute respiratory distress. It died in cardiac arrest while under anaesthesia for surgical removal of a mediastinal abscess. Spermatozoa were flushed from the ductus deferens with $0.9 \%(\mathrm{w} / \mathrm{v}) \mathrm{NaCl}$, examined briefly for motility and placed in $2 \%$ glutaraldehyde phosphate-buffer, $\mathrm{pH} 7 \cdot 2$. These spermatozoa were examined first by phase-contrast microscopy and later by differential-interference contrast microscopy for mensuration. In the latter preparations spermatozoa of a bull (Bos taurus) were added for morphometric comparison. Samples were also postfixed in $1 \% \mathrm{OsO}_{4}$, dehydrated in a graded series of ethanol dilutions (including $30 \mathrm{~min}$ in $70 \%$ ethanol with $0.3 \%$ uranyl acetate), and embedded in Epon. Thin sections were stained with uranyl acetate and lead citrate and examined in a Jeol $100 \mathrm{CX}$ transmission electron microscope. In addition, a few samples were prepared for scanning electron microscopy by mounting on coverslips with $0 \cdot 1 \%$ polylysine, routine ethanol dehydration, critical point drying, and sputter-coating with gold. These specimens were examined in the upper stage of an ISI-DS130 scanning electron microscope.

After collection of spermatozoa from the ductus deferens, the remainder of the reproductive tract was dissected free and stored in 10\% formaldehyde. Cross-sections of testis as well as the head, body and tail of epididymis were later prepared for routine histology.
} 

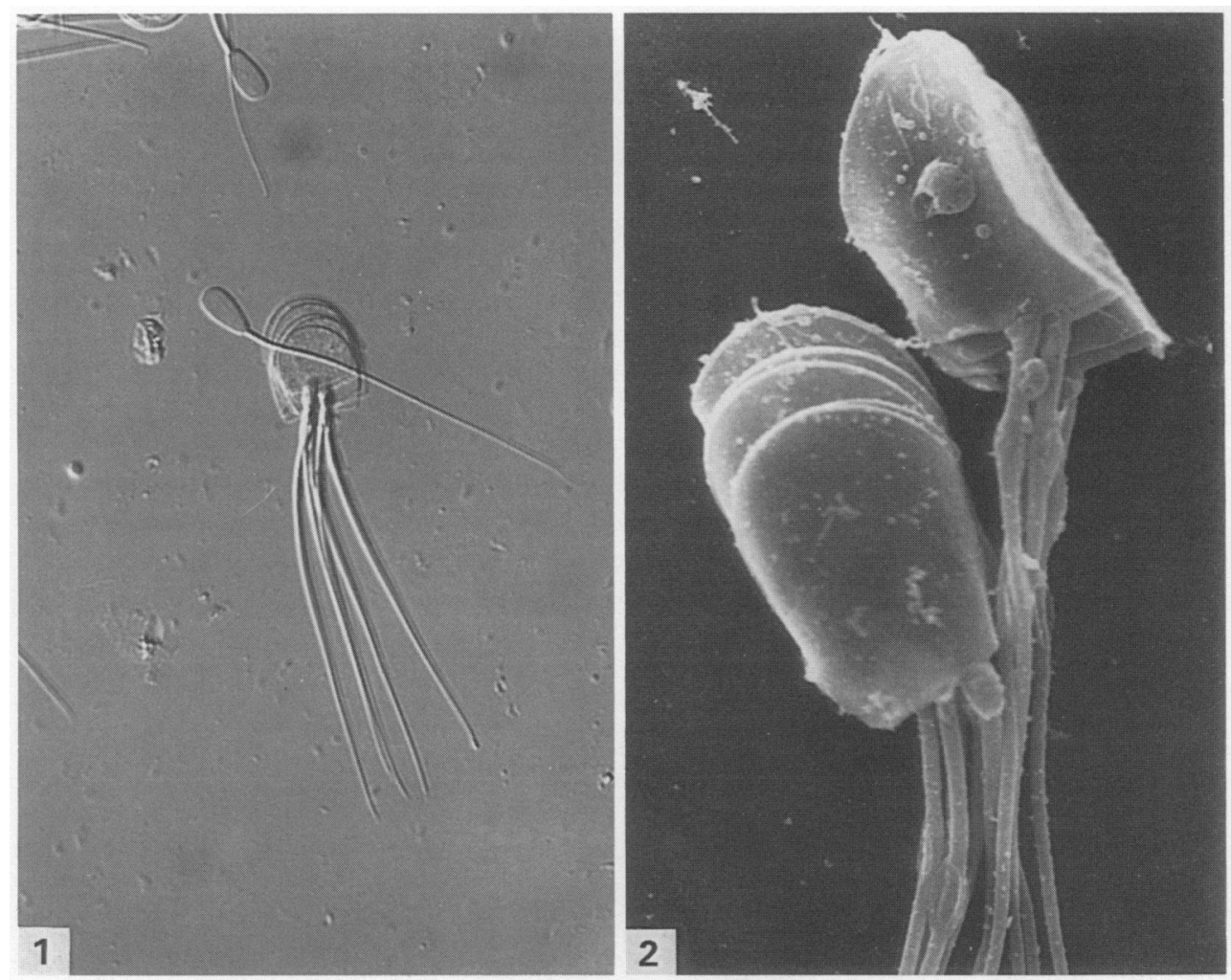

Fig. 1. Differential interference contrast micrograph of a bull (Bos taurus) spermatozoon and a rouleau of armadillo spermatozoa. $\times 550$.

Fig. 2. Scanning electron micrograph of two rouleaux of armadillo sperm heads. $\times 2000$.

\section{Results}

Spermatozoa were immotile at the time of collection. The head of the spermatozoon was flattened into a large wafer-thin spatulate shape with a length of $18 \mu \mathrm{m}$, width of $16 \mu \mathrm{m}$, and thickness of only $0 \cdot 2 \mu \mathrm{m}$. The heads of the spermatozoa were arranged in rouleaux of $4-10$ cells (Figs $1 \& 2$ ). Although the heads were usually flattened in the same plane, occasionally they were curved while still maintaining parallelism between heads in the same stack (Fig. 2). Within rouleaux, the plasma membranes of conjoint spermatozoa were closely related over the acrosomal region, with a uniform interspace between plasma membranes of $10 \mathrm{~nm}$ (Fig. 3).

The nucleus occupied virtually all of the flattened spermhead (Figs 3-5) but composed only one third of its thickness except for a small area near the neck region. Nuclear chromatin was very dense with a paucity of nuclear vacuolation. The acrosome covered two thirds of the nucleus and consisted of an expansive main segment, a modest equatorial segment and only a small acrosomal ridge. The acrosomal ridge expanded both dorsally and ventrally to an equivalent degree (Fig. 3) and extended only along the rostral-most edge of the sperm head. Just inside the acrosomal ridge and resting on the rostral edge of the nucleus, there was a small subacrosomal space containing some dense material.

Considerably more dense subacrosomal material was located beneath the equatorial segment of the acrosome. This material was thick, continuous, and in close relationship to the nuclear 


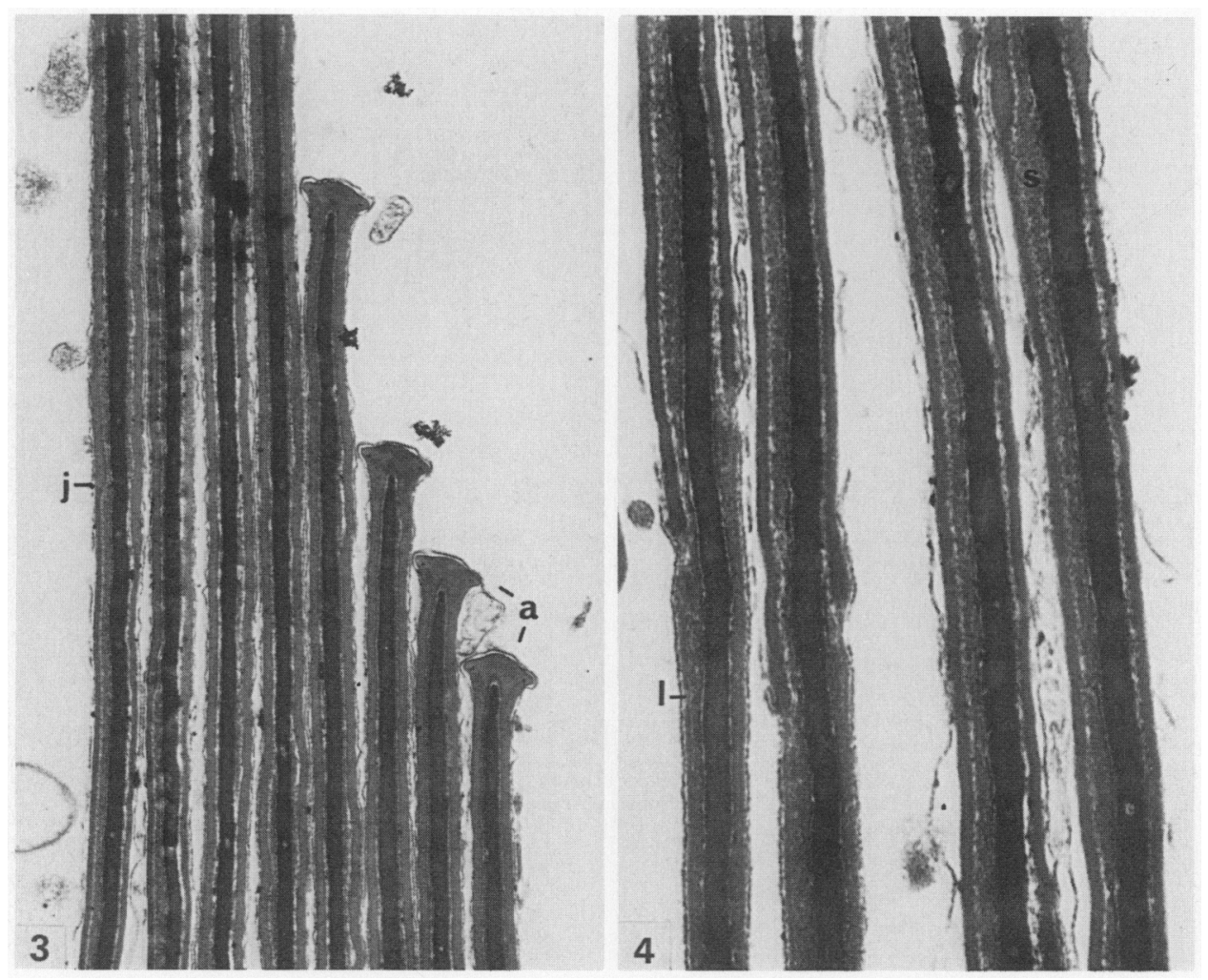

Fig. 3. Cross-section of a rouleau of armadillo spermatozoa showing acrosomal ridges (a), main segments, and junctions of main and equatorial segments $(j) . \times 21600$.

Fig. 4. Cross-section of a rouleau of spermatozoa showing the equatorial segment and unilateral subacrosomal material (s), as well as the postacrosomal regions with the membranous feature (1) enclosed in the postacrosomal dense lamina. $\times 41400$.

membranes on only one side of the nucleus (Figs $4 \& 5$ ). On this surface the acrosome extended more distally than on the contralateral surface. On the contralateral surface, periodic densities were occasionally arranged along the outer edge of the acrosomal equatorial segment (Fig. 5).

The postacrosomal region also had some unique features. The postacrosomal dense lamina was well developed and equally present on both surfaces of the nucleus. Proximally and at the margins of the flattened nucleus, the postacrosomal dense lamina was relatively thick and homogeneous. More centrally and throughout most of the postacrosomal region, however, the dense lamina was narrower and had a distinct membranous feature within it (Figs $4 \& 5$ ). In cross-section, this intralaminar membrane had a clear trilamellar structure. This intralaminar membrane was equidistant from the plasma membrane outside and the nuclear membranes inside.

The neck region of the spermatozoon consisted of structures characteristic of mammals generally. The tail was attached either centrally or slightly eccentrically. There was a basal plate, a proximal centriole, and a related connecting piece from which the major and minor striated columns arose.

The tail of the spermatozoon had an overall length of $80 \mu \mathrm{m}$ with one quarter of that consisting of the midpiece (Fig. 1). Many of the spermatozoa in this collection from the ductus deferens included a cytoplasmic droplet still attached along the distal third of the midpiece (Fig. 6). 


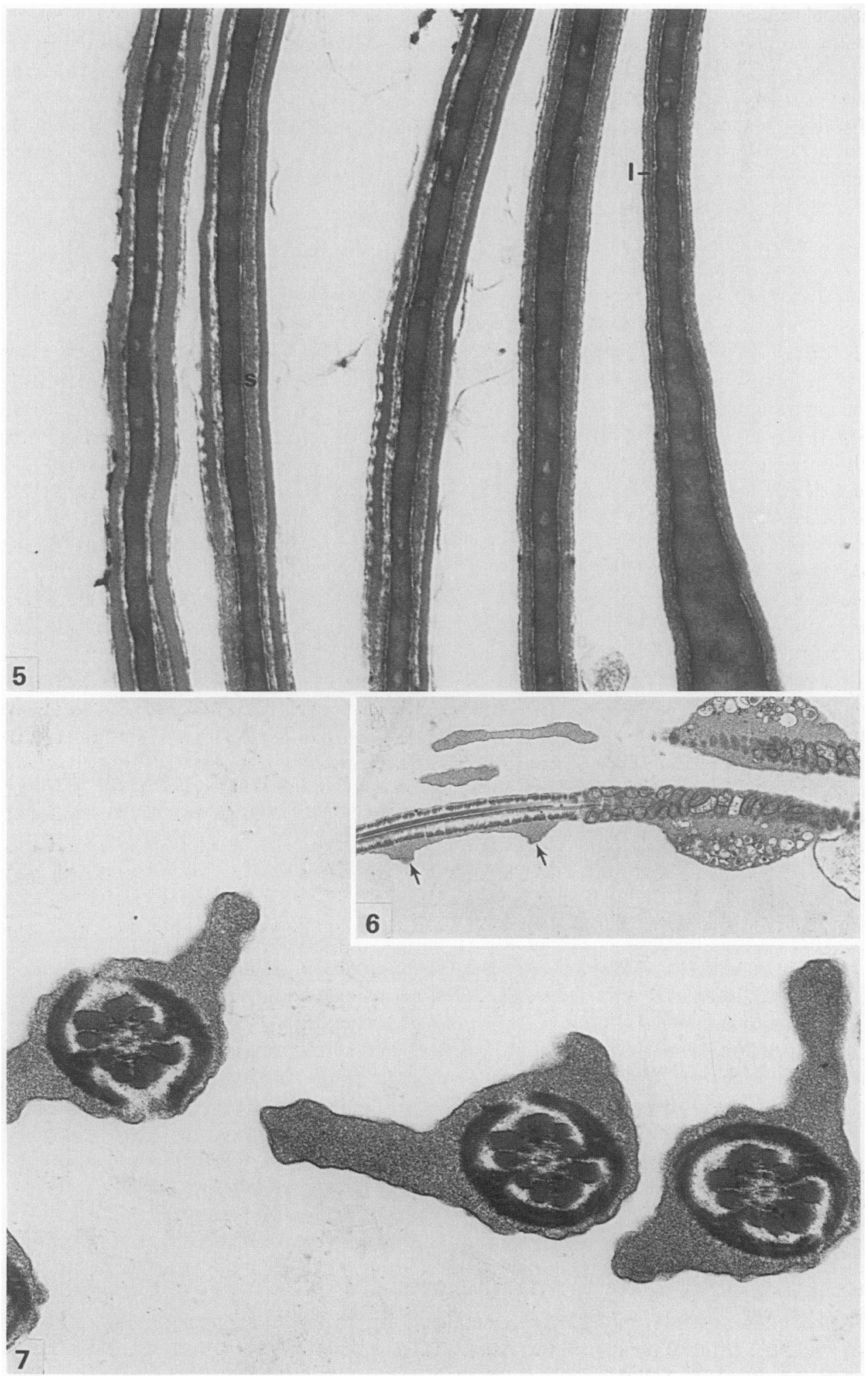


Additional small cytoplasmic projections were also occasionally present more distally on the beginning of the principal piece. Unlike the cytoplasmic droplet, however, these more distal projections did not contain any membranous material or remnants of recognizable organelles. In cross-sections of the proximal principal piece, these unusual projections looked like fins (Fig. 7).

Histological sections of testis and epididymis did not provide any additional information on the structure of individual spermatozoa. Rouleaux of spermatozoa like those collected from the ductus deferens were only seen within the tail of the epididymis.

\section{Discussion}

Although the tail of the spermatozoon of the naked-tail armadillo is not much longer than that of the spermatozoon of a bull (Bos taurus), the overall area provided by the surface of the flattened head is four times that in the bull (Fig. 1). The thickness of the head is about half that of the bull. Nagy \& Edmonds (1973) have described the spermatozoa of the nine-banded armadillo (Dasypus novemcinctus) as having paddle-shaped heads, ensiform in sagittal profiles. Cummins \& Woodall (1985) have given dimensions for the latter of $9 \mu \mathrm{m}$ in length and $6 \mu \mathrm{m}$ in width, which is only slightly larger than those of the bull. Of the 284 mammalian species reviewed by Cummins \& Woodall (1985), only the domestic guinea-pig (Cavia porcellus) has a head shape approaching that of the naked-tail armadillo, with dimensions of $11 \mu \mathrm{m}$ in length and $10 \mu \mathrm{m}$ in width. However, much of this head in Cavia spermatozoa, is occupied by a large acrosomal ridge and does not include the nucleus (Fawcett, 1965).

The naked-tail armadillo is only the third mammalian species in which rouleaux formation by sperm heads has been observed. The other two species are the guinea-pig (Cavia porcellus) and the flying squirrel (Glaucomys volans). In the guinea-pig as in the naked-tail armadillo, the rouleaux involve a very close juxtaposition or cohesion over the acrosomal regions, with a uniform interspace between plasma membranes of $10 \mathrm{~nm}$, as observed by transmission electron microscopy (Friend \& Fawcett, 1974). In the flying squirrel, spermatozoa are first arranged into cylinders within the epididymal duct of the head of the epididymis (Martan \& Hruban, 1970). Each cylinder has sperm heads orientated towards the epididymal epithelium and tails orientated centrally. Rouleaux form later as the cylinders fragment. Rouleaux of spermatozoa are carried along the duct within the body and tail of the epididymis. Rouleaux apparently form earlier in the epididymis of the flying squirrel than in the guinea-pig or naked-tail armadillo. Martan \& Hruban (1970) did not give dimensions for individual flying squirrel sperm heads, but their light micrographs do indicate that the heads are spatulate-shaped. The formation of rouleaux is probably related to the spatulate nature of the sperm heads in all three species.

Although it is not known whether rouleaux formation by spermatozoa in the epididymal duct is of some functional significance in these three species, it has been suggested that a similar cohesive event which occurs between pairs of spermatozoa in new world opposums may serve to protect acrosomes during epididymal passage (Phillips, 1974). Separation of paired spermatozoa in the oviduct of the opossum (Didelphis virginiana) is associated with vacuolar changes in the acrosomes (Rodger \& Bedford, 1982). It is a remarkable biological parallelism, that cohesion between sperm

Fig. 5. Cross-section of a rouleaux of spermatozoa showing (from left to right) one acrosomal main segment, two acrosomal equatorial segments, and three postacrosomal regions. s, unilateral subacrosomal material; 1 , membranous feature in the postacrosomal dense lamina. $\times 23000$.

Fig. 6. Longitudinal section of tails showing relationship of the cytoplasmic projections (arrows) distal to the junction of midpiece and principal piece. $\times 6500$.

Fig. 7. Cross-sections of tails from spermatozoa in a rouleaux, showing fin-like distal cytoplasmic projections. $\times 13600$. 
heads occurs in all New World marsupials (resulting in pairing) and in three New World eutherian mammals (resulting in rouleaux formation) during epididymal transit. Cabassous, Cavia and Glaucomys are widely separated taxonomically. Other species within their respective families (including Dasypus novemcinctus in the Dasypodidae have not been reported to have roleaux formation by spermatozoa. Further, cohesion between epididymal spermatozoa has not been reported as a normal event in any Australian marsupial (Harding et al., 1979) or Old World mammal.

\section{References}

Cummins, J.M. \& Woodall, P.F. (1985) On mammalian sperm dimensions. J. Reprod. Fert. 75, 153-175.

Fawcett, D.W. (1965) The anatomy of the mammalian spermatozoon with particular reference to the guinea pig. Z. Zellsforsch. mikrosk. Anat. 67, 279-296.

Friend, D.S. \& Fawcett, D.W. (1974) Membrane differentiations in freeze-fractured mammalian sperm. $J$. Cell Biol. 63, 641-664.

Grassé, P. (1955) Ordre des Édentés. In Traité de Zoologie. Vol. 17, Part 2, pp. 1182-1246. Masson et Cie, Paris.

Harding, H.R., Carrick, F.N. \& Shorey, C.D. (1979) Special features of sperm structure and function in marsupials. In The Spermatozoon, pp. 289-303. Eds. D. W. Fawcett \& J. M. Bedford. Urban and Schwarzenberg, Baltimore.

Martan, J. \& Hruban, Z. (1970) Unusual spermatozoan formations in the epididymis of the flying squirrel. (Glaucomys volans). J. Reprod. Fert. 21, 167-170.

Meritt, D.A. (1985) Naked-tailed armadillos, Cabassous sp. In The Evolution and Ecology of Armadillos, Sloths and Vermilinguas, pp. 389-391. Ed. G. G. Montgomery. Smithsonian Inst., Washington, D.C.
Miles, R., Newman, L. \& Peterson, G. (1982) The management and reproduction of the large hairy armadillo, Chaetophractus villosus, at the National Zoological Park. Int. Zoo Yb. 22, 185-194.

Nagy, F. \& Edmonds, R.H. (1973) Some observations on the fine structure of armadillo spermatozoa. $J$. Reprod. Fert. 34, 551-553.

Phillips, D.M. (1974) Spermiogenesis, p. 58. Academic Press, New York.

Rodger, J.C. \& Bedford, J.M. (1982) Separation of sperm pairs and sperm-egg interaction in the opossum. Didelphis virginiana. J. Reprod. Fert. 64, 171-179.

Rowlands, I.W. \& Weir, B.J. (1984) Order Edentata. In Marshall's Physiology of Reproduction, 4th edn, Vol. I, pp. $494-495$. Ed. G. E. Lamming. Churchill Livingstone, Edinburgh. 